\title{
First Isolation of a Marseillevirus in the Diptera Syrphidae Eristalis tenax
}

\author{
Mondher Boughalmi ${ }^{a}$ Isabelle Pagnier ${ }^{\mathrm{a}}$ Sarah Aherfi ${ }^{\mathrm{a}}$ Philippe Colson ${ }^{\mathrm{a}}$ \\ Didier Raoult ${ }^{a}$ b Bernard La Scola ${ }^{a}$ \\ a URMITE UM63, CNRS 7278, IRD 198, INSERM 1095, Aix-Marseille Université, Marseille, France; \\ bSpecial Infectious Agents Unit, King Abdulaziz University, Jeddah, Saudi Arabia
}

\section{Key Words}

Giant virus · Marseillevirus · Marseilleviridae · Eristalis tenax in the larva internal structures. This study illustrates the putative role of amoeba in lateral gene transfer not only between the organisms it phagocytoses, but also between organisms living in the same environment.

(C) 2013 S. Karger AG, Basel

\begin{abstract}
Objective: Giant viruses and amoebae are common in freshwater, where they can coexist with various insects. We screened insect larvae to detect giant viruses using a highthroughput method. Methods: We analyzed 86 Eristalis tenax larvae obtained from stagnant water reservoirs in Tunisia. The larvae were decontaminated and then dissected to remove internal parts for coculture with Acanthamoeba polyphaga. Genome sequencing of isolated viruses was performed on a 454 Roche instrument, and comparative genomics were performed. Results: One Marseillevirus, named Insectomime virus, was isolated. The genome assembly generated two scaffolds, which were 382,776 and 3,855 bp in length. Among the 477 identified predicted proteins, the best hit for 435 of the identified proteins was a Marseillevirus or Lausannevirus protein. Tunisvirus was the most closely related to Insectomime, with 446 orthologs. One Insectomime protein shared with Lausannevirus and Tunisvirus showed the highest similarity with a protein from an aphid. Conclusion: The isolation of a Marseillevirus from an insect expands the diversity of environments in which giant viruses have been isolated. The coexistence of larvae and giant viruses in stagnant water may explain the presence of the giant virus
\end{abstract}

\section{Introduction}

The order Megavirales is composed of unusual viruses in terms of the size of their viral particles and the size [1, 2] and contents of their genomes; these characteristics of this order differ considerably from the canonical definition of viruses [3]. These viruses are found in different ecological niches $[4,5]$, reflecting their ability to adapt to different environmental conditions and physico-chemical stress, such as hypersalinity [6].

Of the amoeba-associated giant viruses, Megavirales are represented by the families Mimiviridae [1] and Marseilleviridae [7]. The founder of these two families is Marseillevirus [8]. Amoebae occupy several environmental ecological niches and are commonly found in freshwater, where they can coexist with the larvae of several insect species. Amoebae can be found ubiquitously, under various environmental conditions, such as freshwater, marine water, soil, vertebrates, aerial parts of plants and animals [9]. Some species have been isolated from extreme

\begin{tabular}{ll}
\hline KARGER & $\begin{array}{l}\text { ○ 2013 S. Karger AG, Basel } \\
0300-5526 / 13 / 0566-0386 \$ 38.00 / 0 \quad \text { Karger }\end{array}$ \\
E-Mail karger@karger.com & $\begin{array}{l}\text { This is an Open Access article licensed under the terms of the } \\
\text { Creative Commons Attribution-NonCommercial 3.0 Un- } \\
\text { ported license (CC BY-NC) (www.karger.com/OA-license), } \\
\text { applicable to the online version of the article only. Distribu- } \\
\text { tion permitted for non-commercial purposes only. }\end{array}$
\end{tabular}

Prof. Bernard La Scola, Pôle des Maladies Infectieuses

Assistance Publique-Hôpitaux de Marseille and Aix-Marseille Université URMITE UM63, CNRS 7278, IRD 198, INSERM 1095, Faculté de Médecine 27, boulevard Jean-Moulin, FR-13385 Marseille Cedex 05 (France)

E-Mail bernard.la-scola@univ-amu.fr 
environments, such as hypersaline [10] or hyperthermic [11] conditions. Acanthamoeba have also been described colonizing insects [12]. For some other insect species, such as the syrphid fly Eristalis tenax (Diptera: Syrphidae), eggs normally remain on the surface of water. Larval development is represented by three stages of metamorphosis, larvae, pupas and imago, which have all been demonstrated to be potential vectors for microbial pathogens [13]. E. tenax is also important in some cases of intestinal, nasal, genital and urinary myiasis [14-17]. The three stages of metamorphosis occur in aquatic environments, such as stagnant water, and are in contact with the same environment as amoebae. The immature form of $E$. tenax is referred to as a rat-tailed maggot. The adult form is commonly known as the drone fly and is part of the population of pollinators. The decline in the numbers of these insects is continuing and has significant environmental and economic consequences, mainly because of their great agronomic impact [18]. Several studies have explained that this decline is due to multiple factors, including exposure to pesticides, land use changes, decreasing genetic diversity and climate change $[19,20]$. The increasingly frequent presence of several types of parasites in pollinator insects may also be important. Parasites are important in exerting selection pressure for most organisms, including insects. Some insect parasites are highly virulent and cause diseases with evident symptoms, such as the fungi Metarhizium spp. and Ascosphaera spp., which infect several species of arthropods, including termites and bees [21-23]. Other parasites have less obvious pathological consequences, such as the intracellular bacteria Wolbachia spp., which is widespread in insects. Wolbachia spp. has been shown to have a major impact on the physical condition of the host by manipulating the sex ratio or by adversely affecting insect survival $[24,25]$. In addition to fungi and bacteria, some viruses can also be identified as parasites of arthropods. For example, members of the families Dicistroviridae and Iflaviridae can infect honey bees, which are pollinator insects [26]. All of these parasites may be responsible for the decrease in the number of pollinator populations and are capable of the interspecies transmission, infection or vectorization of infectious diseases. A recent study of the transcriptome of the insect Lymantria dispar [27] revealed the presence of gene sequences belonging to Mimivirus, which is classified in lineage A of the amoebae-associated mimiviruses within the order Megavirales. This observation raises the question of whether there is a relationship between insect species and giant viruses. We hypothesize that there may be multiple lateral transfers of genes, as was suggested by

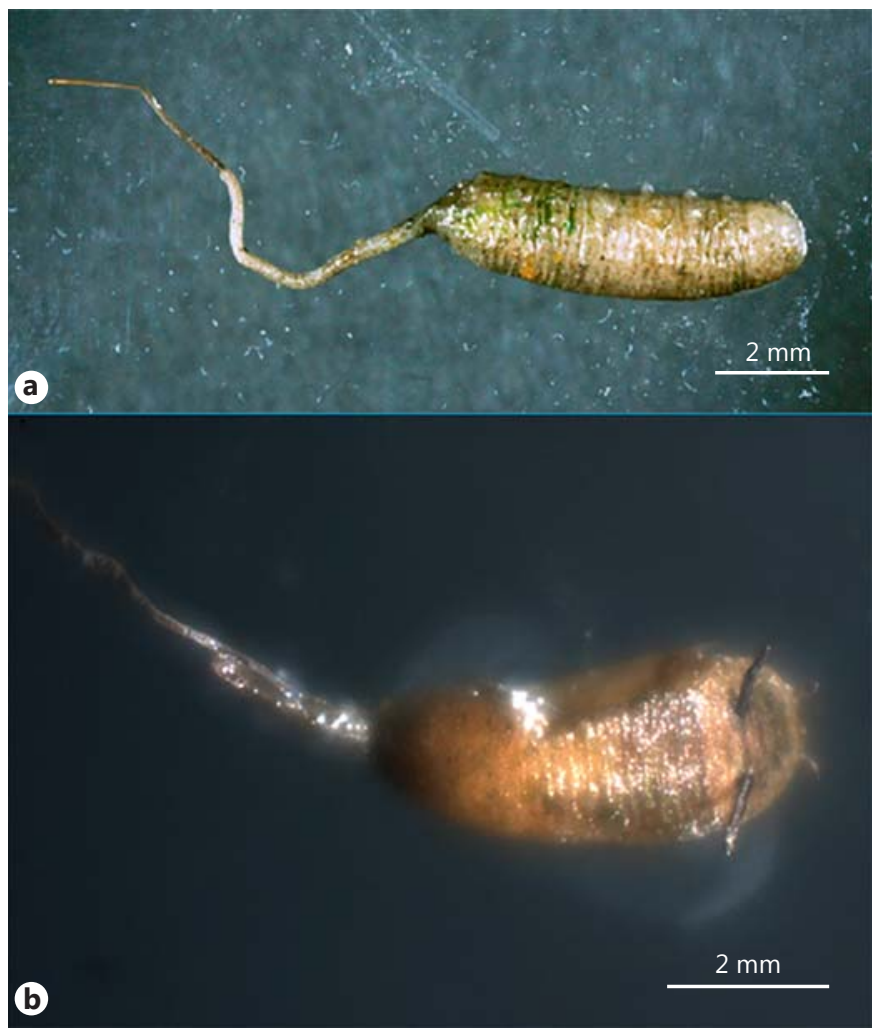

Fig. 1. Morphological identification of larvae: maggots (a) and pupae (b).

Table 1. Sampling sites and characteristics of the samples used for the inoculation of the cocultures

\begin{tabular}{lll}
\hline Samples $(\mathrm{n}=86)$ & Maggots $(\mathrm{n}=46)$ & Pupae $(\mathrm{n}=40)$ \\
\hline Stagnant water tank 1 & 19 & 23 \\
Stagnant water tank 2 & 27 & 17 \\
\hline
\end{tabular}

Bertelli et al. [28]. In our study, we screened several insect larvae to detect the presence of giant viruses using a high throughput detection method. We isolated from a larva of the species E. tenax a new giant virus, which can be classified in the family Marseilleviridae.

\section{Materials and Methods}

\section{Sample Preparation}

Insect larvae were taken from two distinct reservoirs of stagnant water (table 1). There was no renewing of the water, and the ambient temperature was $12^{\circ}$ at the time of sampling, and the wa- 
Fig. 2. Schematic description of the method used to isolate giant viruses from insect larvae.

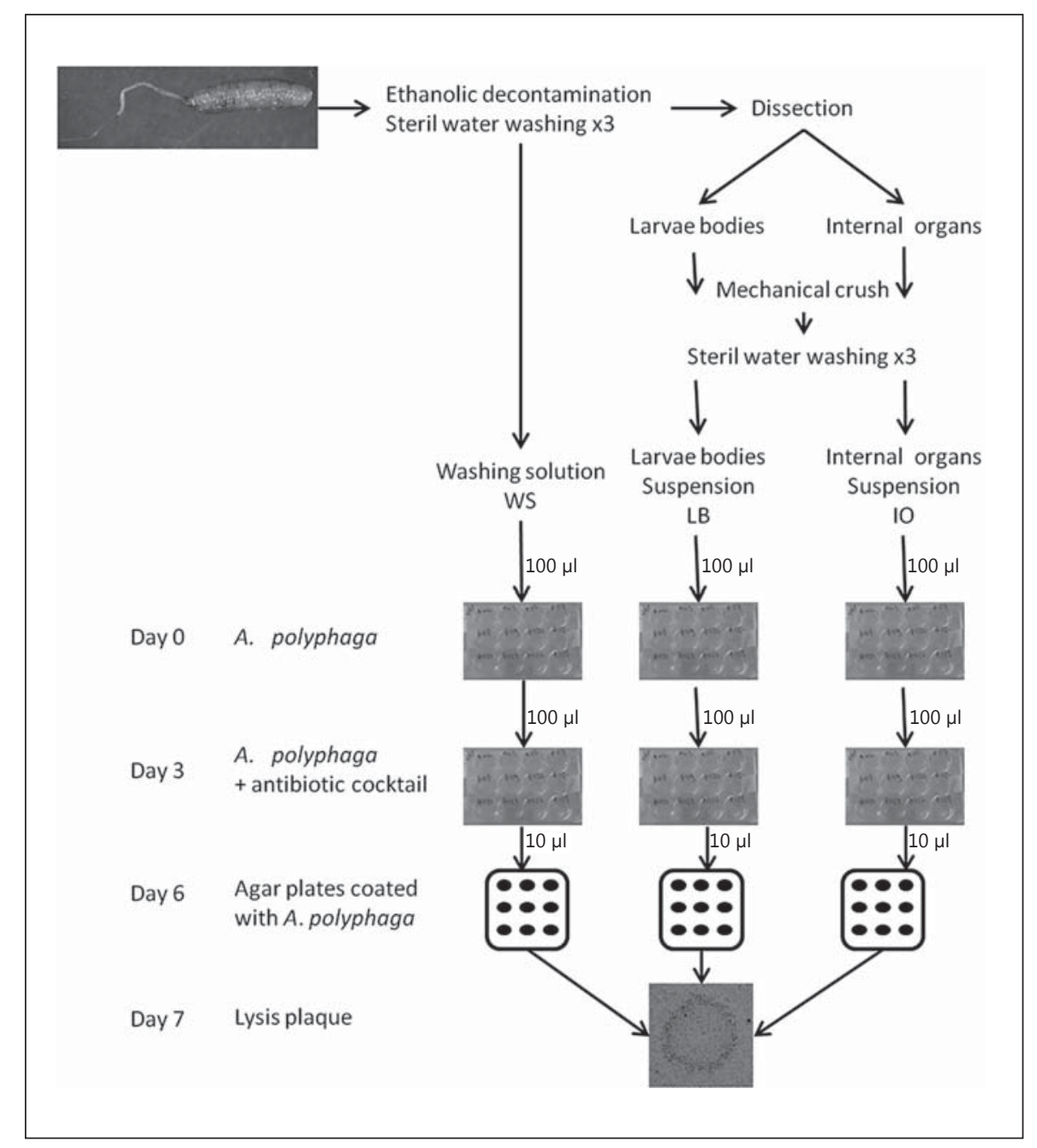

ter temperature was $17^{\circ}$. Those reservoirs were located in the city center of Tunis, Tunisia, which has a Mediterranean climate. Eighty-six larvae of the fly species E. tenax were taken from the backwaters of these reservoirs. To prevent pupation during transportation, wet bottles were used to transport the larvae in high humidity. Identification of the larvae and adult insects was performed morphologically, using the characteristic rat-tailed aspect of the maggots (fig. 1). E. tenax larvae were killed with a $96 \%$ ethanol wash for $20 \mathrm{~min}$, which also decontaminated their surfaces. The larvae were then washed in a washing solution that consisted of sterile Page's amoebal saline (PAS) buffer, and washing suspensions were kept for further investigation. The larvae were dissected as follows: they were wrapped in paraffin and an incision was made on the side of the abdomen with a sterile scalpel, the digestive tract and internal organs were then harvested under sterile conditions and separated from the rest of the larval body. The digestive tract and internal organs $(\mathrm{DT}+\mathrm{IO})$ were crushed mechanically in a sterile mortar with $3 \mathrm{ml}$ of PAS buffer, and the suspension was homogenized. The same treatment was performed for the rest of the larvae bodies (LB). A solution consisting of a mixture of 4 antibiotics [ $10 \mu \mathrm{l}$ of ciprofloxacin at $4 \mathrm{mg} / \mathrm{ml}$ (Pan- pharma, Clairay, France), $10 \mu \mathrm{l}$ of vancomycin at $4 \mathrm{mg} / \mathrm{ml}$ (Mylan, Saint-Priest, France), $10 \mu \mathrm{l}$ of colimycin at $500 \mathrm{IU} / \mathrm{ml}$ (Sanofi Aventis, Paris, France), $10 \mu \mathrm{l}$ of rifampicin at $4 \mathrm{mg} / \mathrm{ml}$ (Sanofi Aventis)] and 1 antifungal agent [10 $\mu \mathrm{l}$ of Fungizone at $100 \mathrm{mg} /$ $\mathrm{ml}$ (Bristol Myers Squibb, Rueil-Malmaison, France)] was added to the suspensions to eliminate bacterial and fungal contamination. The homogenized suspensions of the DT+IO and LB were washed with 5 successive centrifugations at 15,000 rpm for $30 \mathrm{~min}$ and then suspended in PAS buffer to remove traces of the antimicrobial solution. The pellets were resuspended in $500 \mu$ l of PAS buffer. The efficiency of the antimicrobial treatment was assessed by inoculating $50 \mu \mathrm{l}$ of the suspension on BCYE agar (Oxoid, Dardilly, France) and Columbia sheep blood agar (BioMérieux SA, Marcy L'Etoile, France). The agar plates were incubated for at least 5 days at $32^{\circ}$.

\section{Giant Virus Research}

One hundred microliters of the final suspensions of the DT+IO and LB were used to study the giant viruses with a high throughput isolation system, as described elsewhere [6], using the amoeba species Acanthamoeba polyphaga, strain Linc-AP1. Briefly, a primary 
Fig. 3. Morphology of the Insectomime virus. a Hemacolor staining of $A$. polyphaga infected by Insectomime virus. $\mathrm{VF}=$ Virus factories. $\mathbf{b}$ TEM image of the isolated virus showing the typical Marseilleviridae particle morphology of Insectomime.
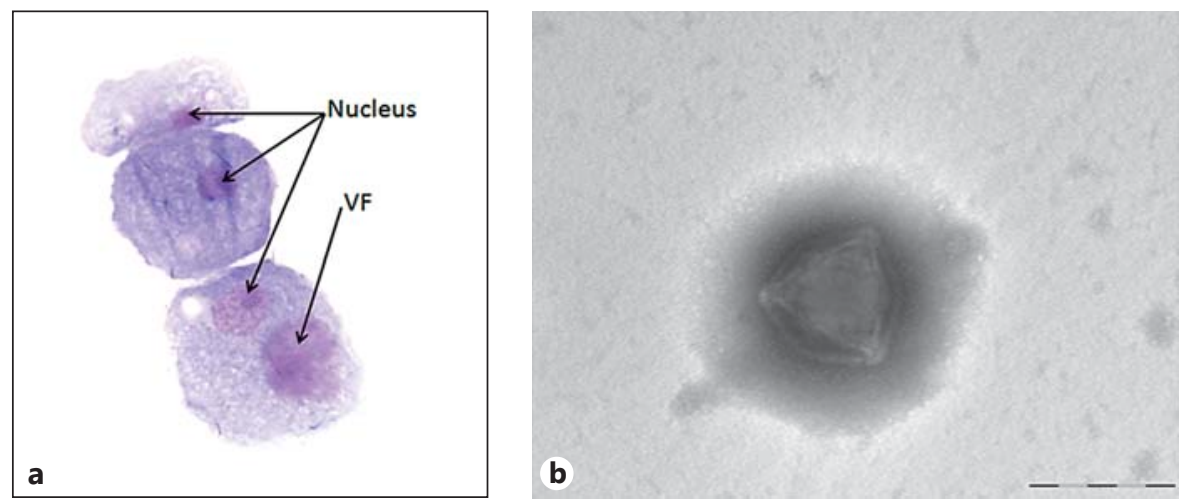

Table 2. Sequences of the primers used for the preliminary molecular identification of Insectomime

\begin{tabular}{llll}
\hline Targeted gene & Primer name & Primer sequence & Temp. $\left(^{\circ}\right)$ \\
\hline Major capsid protein & T19capF & $5^{\prime}$-ATCTCCGGAACGATTCACAG-3' & 60 \\
& T19capR & $5^{\prime}$-TAACTGCTGCTTCCGGTTT-3' & 58 \\
\hline D6 helicase & T19D6/D11F & $5^{\prime}$-AGTTACCCAACCACAAGAAGA-3' & 58 \\
& T19D6/D11R & $5^{\prime}$-CAGAAGGACTAACAAAAGAACCA-3' & 60 \\
\hline
\end{tabular}

culture was made by inoculating $100 \mu \mathrm{l}$ of the sample onto an amoebal monolayer in 12-well microplates without antibiotics. A second enrichment step was performed by subculturing the primary cultures for 3 days on a fresh amoebal monolayer with the addition of the antibiotic cocktail described above that was used for sample decontamination. Finally, these subcultures were inoculated onto agar plates that were coated with an amoebal monolayer. The presence of viruses was assessed through the development of a lysis plaque that was visible to the naked eye. To confirm the presence of giant viruses outside of the larvae, the first washing solutions were systematically centrifuged at $15,000 \mathrm{rpm}$ for $30 \mathrm{~min}$, and the pellet was suspended in $500 \mu \mathrm{l}$ of sterile PAS. Following the first resuspension the pellet was washed five times with successive centrifugations and resuspensions, as described above, to remove traces of ethanol. The final pellet was resuspended in $500 \mu \mathrm{l}$ of sterile PAS and tested for the presence of giant viruses using the same high throughput isolation method. When a lysis plaque was observed on the high-throughput agar plate, agar was cut out of the plaque, divided into small pieces, resuspended in PAS buffer and filtered with a 1.2- $\mu \mathrm{m}$-pore filter. The filtrate was then re-inoculated onto a fresh amoebal monolayer in a 12 -well microplate. The presence of the giant virus in the culture was first assessed by preparing slides with $100 \mu \mathrm{l}$ of culture through cytocentrifugation and Hemacolor staining to determine if the virus was being produced in the infected amoebae. After the culture was lysed, the supernatant was negatively stained with a $3 \%$ ammonium molybdate solution and visualized with an electron microscope. The observed virus was then assessed for a preliminary morphological classification of the family Mimiviridae or Marseilleviridae (fig. 2).

\section{Molecular Detection and Preliminary Identification of} the Isolated Giant Viruses

For the larvae that contained a giant virus, DNA was extracted from $200 \mu$ l of the DT+IO suspension, $200 \mu$ lof the LB suspension and $200 \mu \mathrm{l}$ of the corresponding wash solution. The DNA extraction was performed using a QIAamp DNA Mini Kit (Qiagen, Courtaboeuf, France), according to the manufacturer's instructions. DNA was also extracted from a suspension of the isolated virus for preliminary identification following morphological presumptive characteristics. A PCR reaction was performed, as described elsewhere [6], using primer pairs specific for Marseillevirus (table 2). For positive samples, the same primer pair was used for sequencing in an ABI PRISM 3130XL DNA sequencer (Applied Biosystems). The sequences were assembled and then analyzed with ChromasPro software (Technelysium Pty Ltd.). The assembled sequences were compared with sequences available in the GenBank database using BLAST software (http:// blast.ncbi.nlm.nih.gov/).

\section{Whole Genome Sequencing}

The Insectomime genome was sequenced on a 454 Roche GS20 instrument, as previously described [8]. The reads obtained were assembled de novo with Newbler Assembly software [29]. Protein encoding genes were predicted using the GenemarkS tool [30]. Orthologous genes were searched for using the Proteinortho program [31] and were considered as the best reciprocal hits using a threshold of an e value $<1 \mathrm{e}-3$, an amino acid identity of $>30 \%$ and a coverage of $>70 \%$ on both the query and target sequences. To detect all the orthologs shared with other 


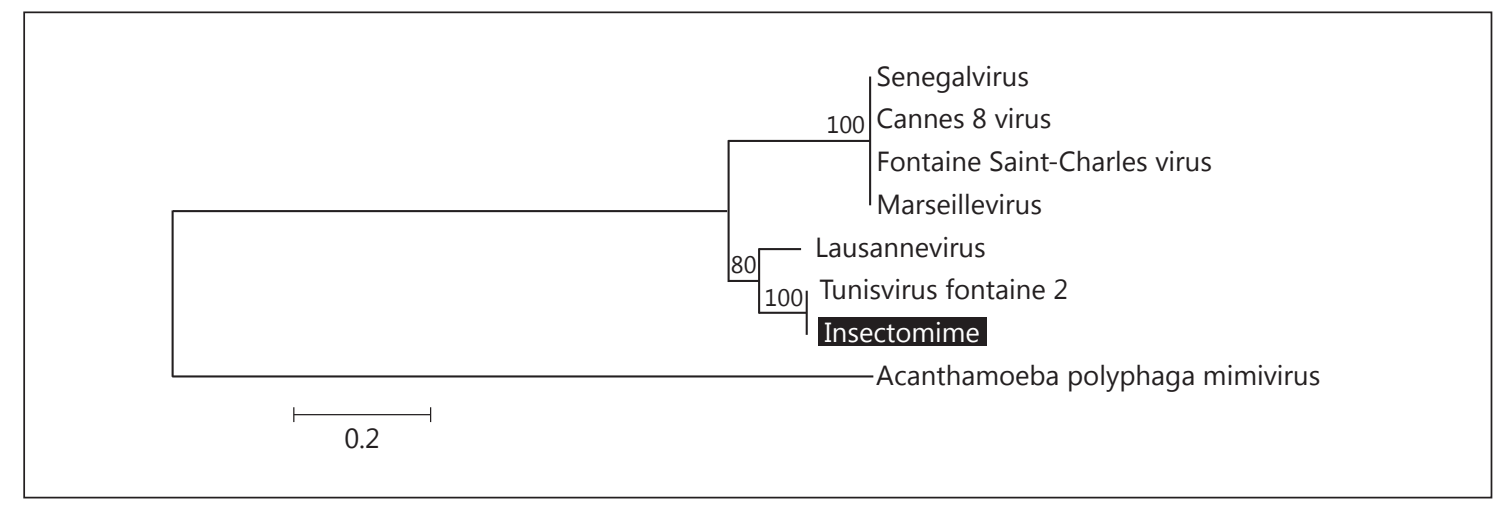

Fig. 4. Phylogenetic reconstruction based on a concatenated alignment of the D6-D11 helicase, the major capsid protein, and the DNA polymerase B family from the members of the family Marseilleviridae. A. polyphaga mimivirus, another member of Megavirales, was used as an outgroup using the maximum likelihood method with Mega 5 software (http://www.megasoftware.net/). The analysis involved a total of 1,580 positions in the final dataset. The probabilities are shown near the branches as percentages and are used as confidence values for the tree branches. The scale bar represents the number of estimated changes per position for a unit of branch length. D6-D11 helicase: Marseillevirus: YP_003406944.1, Lausannevirus: YP_004347182.1; major capsid protein: Marseillevirus: YP_003407071.1, Lausannevirus: YP_004347316.1; DNA polymerase B family: Cannes 8: accession No. JF979175.1, Tunisvirus: GenBank submission grp 4154826, Insectomime: GenBank accession submission ID 1632859, Fontaine Saint-Charles: GenBank accession submission ID 1632860 [6]. marseilleviruses (Marseillevirus [8], Lausannevirus [32] and Tunisvirus fontaine 2 [6]), we performed a non-reciprocal BLASTp search $[33,34]$, using the thresholds $1 \mathrm{e}-4$ for the e value and at least $25 \%$ for both the query and target coverage. Transfer RNA was searched for with the tRNAscan-SE web server [35].

\section{Phylogeny Reconstruction}

To construct a phylogenetic tree, proteic sequences were aligned using MUSCLE software [36], the informational positions were selected using Gblocks [37] and the maximum likelihood phylogeny was performed using MEGA5 software [38]. The phylogeny reconstruction, involving the marseilleviruses and $A$. polyphaga mimivirus as an outgroup, was performed after a concatenation of the selected blocks of the D6-D11 helicase, the major capsid protein, and the DNA polymerase B sequences.

\section{Results}

\section{Isolation and Preliminary Morphological and} Molecular Identification

The use of a high-throughput isolation system allowed for the isolation of a single virus from 86 E. tenax larvae. The virus was isolated from the internal organs and digestive tract of a maggot from reservoir tank 1, but not from the surface of the larvae or the washing solution, either by culture or by PCR. The surface of the viral lysis plaque was $49 \mathrm{~mm}^{2}$ after an incubation time of $12 \mathrm{~h}$. Hemacolor staining of the amoebal coculture showed virus factory accumulation $12 \mathrm{~h}$ after infection (fig. 3a). Measurement with an electron microscope showed an overall viral particle diameter of $225 \mathrm{~nm}$, with a typical icosahedral structure of giant viruses (fig. 3b), suggesting that it was a virus of the family Marseilleviridae. The results of the PCR and sequencing analysis confirmed this classification of the family Marseilleviridae. The virus was called Insectomime.

\section{Whole Genome Sequencing of Insectomime}

Insectomime genome sequencing generated 272,503 reads. Assembly of the reads resulted in 9 large contigs with a mean size of $42,306 \mathrm{bp}$. The contigs assembled themselves in scaffolds of 382,776 and 3,855 bp. The Insectomime draft genome (GenBank submission ID 1632859) is a double-stranded DNA molecule composed of approximately $386,000 \mathrm{bp}$, with a guanine-cytosine content of $42.7 \%$. Phylogeny based on a concatenated alignment of the D6-D11 helicase, the major capsid protein and the DNA polymerase B family sequences showed the position of this virus among previously isolated Marseillevirus, Lausannevirus and Tunisvirus, which is its closest neighbor (fig. 4). A tree constructed based on the family B DNA polymerase exhibited the same topology. Comparative analyses using BLASTp searches of the Insectomime genome and ge- 




Fig. 5. Dot plot between orthologous proteins of Insectomime and Marseillevirus (a), Lausannevirus (b) or Tunisvirus fontaine 2 (c).

nomes of other marseilleviruses showed substantial levels of similarity and collinearity, particularly at the ends of the genome (fig. 5). A total of 477 predicted proteins were tentatively identified in the Insectomime genome, with their sizes varying from 46 to 1,643 amino acids. Of these proteins, 435 were found to be best hits for either a Marseillevirus or a Lausannevirus protein. Insectomime shares 311 and 357 orthologs with Marseillevirus and Lausannevirus, including 260 and 300 bona fide orthologous genes (involved in reciprocal best hits with a sequence coverage $>70 \%$ ), respectively. Of the analyzed marseilleviruses, Tunisvirus appeared to be the most closely related to Insectomime. Insectomime shares 446 orthologs with Tunisvirus, including 345 reciprocal best hits (fig. 5c). Otherwise, 329 Insectomime proteins were annotated as hypothetical proteins, including 293 found either in Marseillevirus or Lausannevirus, two proteins from A. castellanii strain Neff (ACA1_085270) and A. polyphaga moumouvirus (AGC02396.1), and 34 ORFs, with sizes ranging from 103 to 244 amino acids. Several orthologs to serine/protein kinases, proteins containing bacterial-like membrane occupation and recognition nexus repeat domains, histone-like proteins and endonucleases (especially restriction endonucleases and $\mathrm{Vsr} /$ MutH/archaeal HJR family endonucleases) were identified, as was first determined for Marseillevirus [8, 32]. Apart from proteins of the marseilleviruses, best BLASTp hits for eight Insectomime proteins were found in $A$. castellanii, A. polyphaga moumouvirus, an amoebae Mimivirus of the lineage $\mathrm{B}$, a flagellate (Cercomonas spp.), two opisthokonts (Capsaspora owczarzaki, Hydra

Marseillevirus Isolation in E. tenax magnipapillata), a bacterium (Cellulophaga algicola), a phage of a free-living nitrogen-fixing bacterium ( $A z o$ spirillum phage Cd), and in an aphid (Acyrthosiphon pisum). In the aphid case, the Insectomime protein, orf298, is an ankyrin repeat-containing protein that is also found in Lausannevirus (YP_004347163.1) and Tunisvirus (Tunisvirus_orf78). The Insectomime genome encodes 6 ankyrin repeat-containing proteins, which is equivalent to what is found in the Tunisvirus genome but greater than what is found in the genomes of the other marseilleviruses. Eight of the twenty best hits found by a BLASTp search for Insectomime orf 298 against the NCBI GenBank non-redundant protein sequence database matched to putative ankyrin repeatcontaining proteins from Acyrtosiphon pisum. For the top hit (XP_001949966.2), the e value was 7e-9, the amino acid identity was $26 \%$ and the query (Insectomime orf298) and target coverage were 80 and $66 \%$, respectively. The twelve other best target sequences were proteins from Lausannevirus, A. castellanii, three chlorophyta (Ostreococcus lucimarinus, Bathycoccus prasinos and Micromonas pusilla), and a heterokontophyta (Phytophthora infestans) (fig. 6).

\section{Discussion}

We found one giant virus from the recently described family Marseilleviridae [7] in the 86 larvae studied. The virus is phylogenetically distinct from other previously described marseilleviruses, including Marseillevirus [8], 


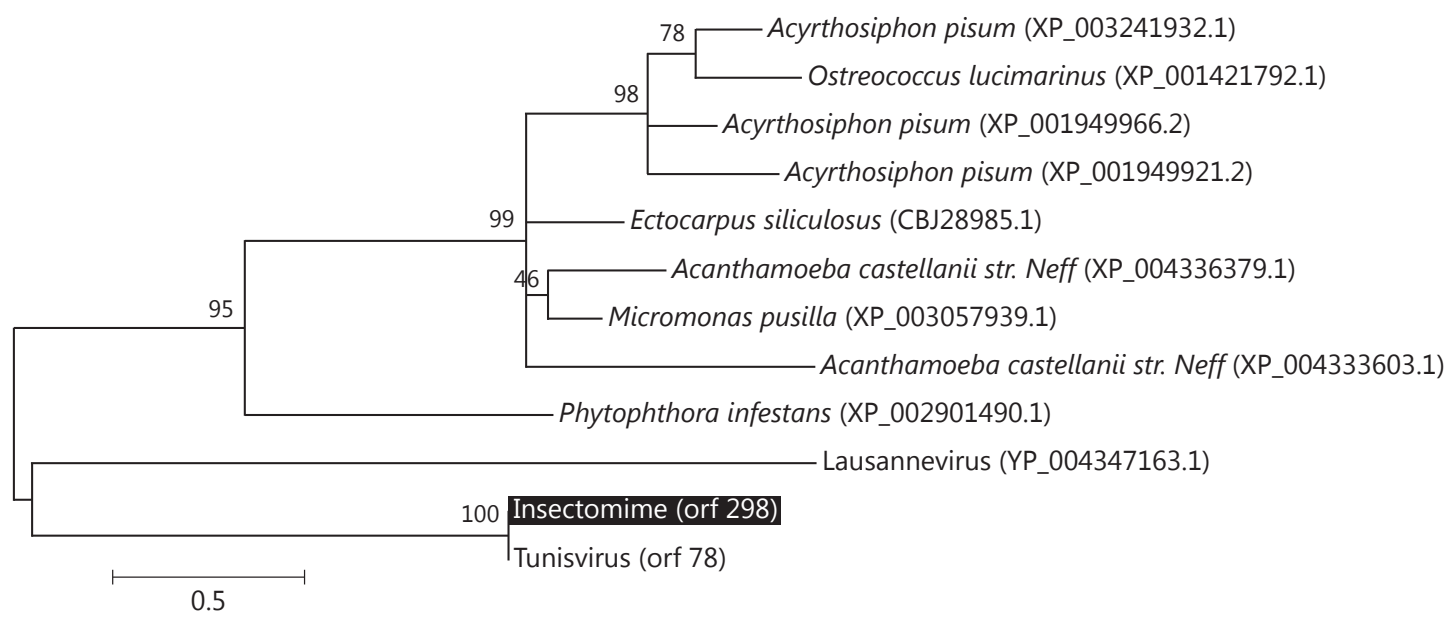

Fig. 6. Phylogenetic reconstruction based on an alignment of an ankyrin repeat-containing protein from Insectomime and orthologous proteins, using the maximum likelihood method with Mega 5 software (http://www.megasoftware.net/). The probabilities are

shown near the branches as percentages and are used as confidence values for the tree branches. The scale bar represents the number of estimated changes per position for a unit of branch length.

Lausannevirus [32], Cannes 8 [unpubl. data] (GenBank submission ID 1632635). Tunisvirus [unpubl. data] (GenBank submission grp 4154826) [6] is the most closely related virus to the new virus. This new virus was found only in the internal organs of the insect, including the digestive tract, and no virus could be found in the surface or in the suspension used to wash the larvae before the experiment. The species E. tenax (Diptera, Brachycera, Muscomorpha, Syrphidae, E. tenax) is an insect with a complex metamorphosis process. The eggs are typically laid on the surface of water and the larvae proceed through three stages of development. Metamorphosis always occurs in an aquatic environment that is rich in organic matter, such as stagnant water reservoirs. As was previously described for amoebae [39], the species E. tenax is also an important vector for several bacterial species, such as Mycobacterium spp. [8], which is responsible for a disease in pigs. To our knowledge, this is the first study demonstrating that a giant virus has been isolated from this species in particular and from an insect in general. The coexistence of larvae and giant viruses in stagnant water may explain the presence of a giant virus in the internal tracts of the larvae. Giant viruses are most often found in aquatic environments $[5,6]$, and the possibility that the virus was ingested by the insect larva might explain its presence in only the internal organs of the animal and not

on the surface. Otta et al. [12] described that amoeba can colonize some insect species; this raises a question about the origin of the virus presence in the insect. The virus could have been directly ingested, or it could have entered the insect through the ingestion of an infected amoeba. The capacity of amoebae to act as 'Trojan horses' has already been described [40] and could explain the presence of the virus in the insect larva. Our findings illustrate the possible role of giant viruses in the transfer of genes between microorganisms, through cocolonization with other microorganisms of the same eukaryotic hosts [41-43]. This study also suggests the multilateral transfer of genes between different species of the same ecological niche, such as insect larvae and amoebae in stagnant water. In the viral genome, among the eight Insectomime proteins having as their best BLASTp hit an organism other than Marseillevirus or Lausannevirus, five proteins belonging to eukaryotes were found. One Insectomime protein harbored a high similarity (e value: $7 \mathrm{e}-9$; coverage: $80 \%$ for the viral protein, $66 \%$ for the insect protein; amino-acid identity: $26 \%$; similarity: $40 \%$ ) to a protein from an insect from the family Aphididae (Acyrthosiphon pisum). Ankyrin repeat domain-containing proteins mediate protein-protein interactions and have been described to be involved in the lateral transfer of genes between eukaryotes and bacteria [44]. In ecological niches, such as reser- 
voirs of stagnant water, amoebae are presented as a 'melting pot', a giant hub for the exchange of genes between amoeba-resistant bacteria, virophages and giant viruses [8]. The data reported here suggest that ankyrin repeat proteins may have undergone a lateral gene transfer between giant viruses in amoebae and insects, especially those having at least an aquatic phase in their developmental cycle and a greater opportunity for contact with amoebae. Future studies can address the effects of the virus on the development and survival of the larvae to eval- uate the impact of this infection on the pollinator populations and to establish the role of emerging viruses in the decline of some nearly extinct populations.

\section{Disclosure Statement}

The authors declare that there is no potential conflict of interest or financial disclosure.

\section{References}

$>1$ Raoult D, Audic S, Robert C, Abergel C, Renesto P, Ogata H, La Scola B, Suzan M, Claverie JM: The 1.2-megabase genome sequence of Mimivirus. Science 2004;306:1344-1350.

-2 La Scola B, Audic S, Robert C, Jungang L, de Lamballerie X, Drancourt M, Birtles R, Claverie JM, Raoult D: A giant virus in amoebae. Science 2003;299:2033.

3 Colson P, de Lamballerie X, Fournous G, Raoult D: Reclassification of giant viruses composing a fourth domain of life in the new order Megavirales. Intervirology 2012;55: 321-332.

4 Yamada T: Giant viruses in the environment: their origins and evolution. Curr Opin Virol 2011;1:58-62.

-5 La Scola B, Campocasso A, N’Dong R, Fournous G, Barrassi L, Flaudrops C, Raoult D: Tentative characterization of new environmental giant viruses by MALDI-TOF mass spectrometry. Intervirology 2010;53:344353.

6 Boughalmi M, Saadi H, Pagnier I, Colson P, Fournous G, Raoult D, La Scola B: Highthroughput isolation of giant viruses of the Mimiviridae and Marseilleviridae families in the Tunisian environment. Environ Microbiol 2013;15:2000-2007.

7 Colson P, Pagnier I, Yoosuf N, Fournous G, La Scola B, Raoult D: 'Marseilleviridae', a new family of giant viruses infecting amoebae. Arch Virol 2013;158:915-920.

$>8$ Boyer M, Yutin N, Pagnier I, Barrassi L, Fournous G, Espinosa L, Robert C, Azza S, Sun S, Rossmann MG, Suzan-Monti M, La Scola B, Koonin EV, Raoult D: Giant Marseillevirus highlights the role of amoebae as a melting pot in emergence of chimeric microorganisms. Proc Natl Acad Sci USA 2009;106: 21848-21853.

$>9$ Rodriguez-Zaragoza S: Ecology of free-living amoeba. Crit Rev Microbiol 1994;20:225241 .
0 Park JS, Simpson AG, Brown S, Cho BC: Ul- 19 Ratnieks FL, Carreck NL: Ecology: clarity on trastructure and molecular phylogeny of two heterolobosean amoebae, Euplaesiobystra hypersalinica gen. et sp. nov. and Tulamoeba peronaphora gen. et sp. nov., isolated from an extremely hypersaline habitat. Protist 2009; 160:265-283.

11 De Jonckheere JF, Baumgartner M, Opperdoes FR, Stetter KO: Marinamoeba thermophila, a new marine heterolobosean amoeba growing at 50 degrees C. Eur J Protistol 2009; 45:231-236.

12 Otta DA, Rott MB, Carlesso AM, da Silva OS: Prevalence of Acanthamoeba spp. (Sarcomastigophora: Acanthamoebidae) in wild populations of Aedes aegypti (Diptera: Culicidae). Parasitol Res 2009;111:2017-2022.

13 Fischer OA, Mátlová L, Dvorská L, Svástová P, Bartos M, Weston RT, Pavlík I: Various stages in the life cycle of syrphid flies (Eristalis tenax; Diptera: Syrphidae) as potential mechanical vectors of pathogens causing mycobacterial infections in pig herds. Folia Microbiol 2006;51:147-153.

14 Raffray L, Malvy D: Accidental intestinal myiasis caused by Eristalis tenax in France. Travel Med Infect Dis 2013, E-pub ahead of print.

15 Salimi M, Edalat H, Jourabchi A, Oshaghi M: First report of human nasal myiasis caused by Eristalis tenax in Iran (Diptera: Syrphidae). Iran J Arthropod Borne Dis 2010;4:77-80.

-16 González M, Comte MG, Monárdez PJ, Díaz de Valdés LM, Matamala CI: Accidental genital myiasis by Eristalis tenax. Rev Chilena Infectol 2009;26:270-272.

-17 Mumcuoglu I, Akarsu GA, Balaban N, Keles I: Eristalis tenax as a cause of urinary myiasis. Scand J Infect Dis 2005;37:942-943.

18 Golding YC, Ennos AR, Edmunds M: Similarity in flight behaviour between the honeybee Apis mellifera (Hymenoptera: apidae) and its presumed mimic, the dronefly Eristalis tenax (Diptera: syrphidae). J Exp Biol 2001;204: 139-145. honey bee collapse? Science 2010;8:152-153.

20 Potts SG, Biesmeijer JC, Kremen C, Neumann P, Schweiger O, Kunin WE: Global pollinator declines: trends, impacts and drivers. Trends Ecol Evol 2010;25:345-353.

-21 Bérénos C, Schmid-Hempel P, Wegner KM: Evolution of host resistance and trade-offs between virulence and transmission potential in an obligately killing parasite. J Evol Biol 2009; 22:2049-2056.

22 Aronstein KA, Murray KD: Chalkbrood disease in honey bees. J Invertebr Pathol 2010; 103:S20-S29.

23 Evison SE, Roberts KE, Laurenson L, Pietravalle S, Hui J, Biesmeijer JC, Smith JE, Budge G, Hughes WO: Pervasiveness of parasites in pollinators. PLoS One 2012;7:e3064.

24 Hilgenboecker K, Hammerstein P, Schlattmann P, Telschow A, Werren JH: How many species are infected with Wolbachia? A statistical analysis of current data. FEMS Microbiol Lett 2008;281:215-220.

25 Werren J: Biology of Wolbachia. Annu Rev Entomol 1997;42:587-609.

26 Evans JD, Schwarz RS: Bees brought to their knees: microbes affecting honey bee health. Trends Microbiol 2011;19:614-620.

27 Sparks ME, Gundersen-Rindal D: The Lymantria dispar IPLB-Ld652Y cell line transcriptome comprises diverse virus-associated transcripts. Viruses 2011;3:2339-2350.

28 Bertelli C, Greub G: Lateral gene exchanges shape the genomes of amoeba-resisting microorganisms. Front Cell Infect Microbiol 2012;2:110.

29 Margulies M, Egholm M, Altman WE, et al: Genome sequencing in microfabricated highdensity picolitre reactors. Nature 2005;437: 376-380.

30 Besemer J, Borodovsky M: GeneMark: Web software for gene finding in prokaryotes, eukaryotes and viruses. Nucleic Acids Res 2005; 33:W451-W454. 
31 Lechner M, Findeiss S, Steiner L, Marz M, Stadler PF, Prohaska SJ: Proteinortho: detection of (co-)orthologs in large-scale analysis. BMC Bioinformatics 2011;12:124.

- 32 Thomas V, Bertelli C, Collyn F, Casson N, Telenti A, Goesmann A, Croxatto A, Greub G: Lausannevirus, a giant amoebal virus encoding histone doublets. Environ Microbiol 2011;13:1454-1466.

33 Desnues C, La Scola B, Yutin N, Fournous G, Robert C, Azza S, Jardot P, Monteil S, Campocasso A, Koonin EV, Raoult D: Provirophages and transpovirons as the diverse mobilome of giant viruses. Proc Natl Acad Sci USA 2012;109:18078-18083.

-34 Altschul SF, Gish W, Miller W, Myers EW, Lipman DJ: Basic local alignment search tool. J Mol Biol 1990;215:403-410.
5 Schattner P, Brooks AN, Lowe TM: The tRNAscan-SE, snoscan and snoGPS web servers for the detection of tRNAs and snoRNAs. Nucleic Acids Res 2005;33:W686-W689.

36 Edgar RC: Muscle: multiple sequence alignment with high accuracy and high throughput. Nucleic Acids Res 2004;32:1792-1797.

37 Castresana J: Selection of conserved blocks from multiple alignments for their use in phylogenetic analysis. Mol Biol Evol 2000;17: 540-552.

38 Tamura K, Peterson D, Peterson N, Stecher G, Nei M, Kumar S: MEGA5: molecular evolutionary genetics analysis using maximum likelihood, evolutionary distance, and maximum parsimony methods. Mol Biol Evol 2011;28:2731-2739.

39 Salah IB, Ghigo E, Drancourt M: Free-living amoebae, a training field for macrophage resistance of mycobacteria. Clin Microbiol Infect 2009;15:894-905.
40 Greub G, Raoult D: Microorganisms resistant to free-living amoebae. Clin Microbiol Rev 2004;17:413-433.

41 Raoult D, Boyer M: Amoebae as genitors and reservoirs of giant viruses. Intervirology 2010; 53:321-329.

42 Thomas V, Greub G: Amoebae/amoebal symbionts genetic transfers: lessons from giant virus neighbours. Intervirology 2010;53:254267.

43 Moliner C, Fournier PE, Raoult D: Genome analysis of microorganisms living in amoebae reveals a melting pot of evolution. FEMS Microbiol Rev 2010;34:281-294.

44 Al-Khodor S, Price CT, Kalia A, Abu Kwaik Y: Functional diversity of ankyrin repeats in microbial proteins. Trends Microbiol 2010; 18:132-139. 